\title{
(C) OPEN ACCESS \\ Success in the city: the road to implementation of Tobacco 21 and Sensible Tobacco Enforcement in New York City
}

\author{
Sarah Moreland-Russell, ${ }^{1}$ Todd Combs, ${ }^{1}$ Kevin Schroth, ${ }^{2}$ Douglas Luke ${ }^{1}$
}

${ }^{1}$ Center for Public Health Systems Science, Brown School at Washington University in St. Louis, St. Louis, Missouri, USA

${ }^{2}$ NYC Department of Health \& Mental Hygiene, Bureau of Chronic Disease Prevention and Tobacco Control, New York City, New York, USA

\section{Correspondence to}

Dr Sarah Moreland-Russell, Brown School at Washington University in St. Louis, Campus Box 1196, 1 Brookings Drive, St. Louis, MO 63130, USA; Smoreland-russell@wustl.edu

Received 30 March 2016 Revised 19 April 2016

Accepted 20 April 2016

\section{ABSTRACT}

New York City, a leader in municipal tobacco control in the USA, furthered its goal of reducing the community's burden of tobacco use in 2014 by implementing Sensible Tobacco Enforcement and Tobacco 21. These policies are intended to restrict youth access and eliminate sources of cheap tobacco. Strong partnerships, substantial local data and support from the public and elected officials were key in overcoming many challenges and ensuring these policies were signed into law.

\section{BACKGROUND}

In 2014, New York City (NYC), in an effort to reduce accessibility of cheap tobacco particularly for youth, implemented two of the most progressive point-of-sale (POS) laws in the nation. This followed a decade of successive tax increases, a proven method to decrease access to cheap tobacco, ${ }^{1}$ which coincided with, and likely contributed to, increased availability of illegal (untaxed) cigarettes. The first law, Tobacco 21, raised the minimum age to purchase tobacco, including e-cigarettes, from 18 to 21 years. The second law, Sensible Tobacco Enforcement (STE), included a comprehensive set of price-related policies that restricted price discounts, established minimum price and packaging requirements, and increased penalties for tax evasion. The city's ambitious goal of reducing the availability of cheap tobacco was not easy to achieve. It overcame challenges common to cities working on POS policies with the help of strong partnerships, convincing local data and support from elected officials and lawyers. ${ }^{2}$ This paper describes research that supported these laws and how local partnerships and stakeholders helped to enact and implement them.

\section{RESEARCHING POSSIBLE POLICY STRATEGIES Minimum legal sale age policies}

Minimum legal sale age (MLSA) policies reduce access to tobacco by restricting sales to young people. In total, 95\% of adult daily smokers are younger than 21 when they have their first cigarette, and $90 \%$ of cigarettes bought for minors come from people aged $18-20$ years. ${ }^{3-6}$ Raising the MLSA had been a tobacco control goal in NYC since 2005, when council member James Gennaro proposed raising the age to 19 . At the time, there was little political support or data supporting the approach. While the Family Smoking Prevention and Tobacco Control Act (FSPTCA, 2009) expressly prohibits the federal government from increasing the MLSA higher than 18, it also confirms that local jurisdictions retain the authority to legislate higher MLSAs. Four states (Alaska, Alabama, Utah and New Jersey) have MLSAs set at $19,^{7}$ and in 2005, Needham, Massachusetts, became the first city in the USA to raise its MLSA to $21 .^{8}$ In 2015 , the Institute of Medicine released additional compelling evidence supporting Tobacco 21 laws. $^{9}$

\section{Price discount policies}

Tobacco is widely available in convenience stores, supermarkets, gas stations, pharmacies and other retailers. An estimated 375000 businesses sell tobacco in the contiguous USA, the equivalent of 27 tobacco retailers for every McDonald's. ${ }^{10}$ The pervasiveness of tobacco products and conspicuously advertised price discounts makes purchases easier, and attracts new and younger users, encourages continued use and lessens chances of successful quit attempts. ${ }^{11} 12$ Discounts on tobacco products increase accessibility for price-sensitive consumers, including members of vulnerable populations such as African-Americans, low-income groups, youth and women. ${ }^{13}$

\section{Minimum price laws}

Minimum price laws for tobacco products can also restrict access to cheap tobacco or eliminate cheap products altogether. Although 24 states and the District of Columbia have had minimum price laws in place for decades, many of these are unnecessarily complicated, vulnerable to industry and retailer manipulation, and ineffective at increasing prices at the POS. ${ }^{14}$ Most minimum price laws are based on minimum mark-ups, meaning that the state requires retailers and/or wholesalers to add a certain percentage of their cost to the final price at the POS. ${ }^{14} 15$ To circumvent these types of minimum price laws, tobacco companies simply lower base prices or offer discount programmes. Instead of minimum mark-up laws, studies have shown that it may be more effective to establish a flat minimum rate (also called a price floor) for specific products to limit industry influence on price more directly. ${ }^{15}$

\section{Minimum packaging sizes}

Setting the minimum number of products per package reinforces the effectiveness of price discount restrictions and minimum price laws. ${ }^{16}$ Although the FSPTCA requires cigarettes to be sold in packs of 20, federal laws do not regulate pack sizes for other tobacco products such as cigars and cigarillos. States and municipalities can combat accessibility to cheap cigars and other tobacco 
products through minimum packaging requirements. ${ }^{17}$ In 2011 , Boston, Massachusetts, passed a minimum packaging requirement for cigars. The ordinance stipulates that cigars and cigarillos priced under $\$ 2.50$ at retail must be sold in packs of at least four. $^{18}$

\section{UNDERSTANDING THE PROBLEM LOCALLY AND GAINING BUY-IN}

Beginning in 2011, the Department of Health \& Mental Hygiene (referred to as 'the Department') team researched and conducted surveys to assess the prevalence of cheap and discounted tobacco in the city. Staff members used coupons to buy tobacco products in bodegas around the city and created a visual display using poster board to demonstrate the range of savings a smoker may experience through sales discounts. These displays were used to educate stakeholders and decision-makers, who were consistently surprised at the low prices and extent of discounting practices. ${ }^{19}$ In addition, when compelling evidence emerged from Needham, Massachusetts, the first US town with a Tobacco 21 law, the team built Tobacco 21 into its overall strategy. $^{20}$

\section{Developing strong partnerships within and beyond city government}

On the basis of the rationale that cigarette tax evasion is a health issue and a law enforcement issue, the Department forged key partnerships early for crafting policies. Staff and leaders reached out to the city agencies that would play roles in implementation and enforcement-the Departments of Finance and Consumer Affairs. The Sheriff's Office, a division of Department of Finance, enforces cigarette tax laws through retail inspections, and Consumer Affairs issues the city's retailer licences and performs most in-store retail licence inspections. This interagency collaboration became a productive strategy throughout the policymaking process. ${ }^{16}$ In addition, the support of council member Gennaro, who first proposed raising the age for tobacco sales in 2005, facilitated stakeholder engagement.

Forging alliances with non-governmental partners was another key element of NYC's success in the development of STE and Tobacco 21. National voluntary organisations including the American Cancer Society Cancer Action Network, American Heart Association, American Lung Association and the Campaign for Tobacco-Free Kids corralled support for both policies. In addition, the Tobacco Control Legal Consortium, a national legal network that supports municipalities in tobacco control policy work, provided technical assistance. The experiences of Needham, Massachusetts, and Providence, Rhode Island, which had passed a law similar to NYC's tobacco discount ban, provided evidence of similar policies' success in other communities.

Several local coalitions including NYC Smoke-Free (then known as the NYC Coalition for a Smoke-Free City), the Lesbian, Gay, Bisexual \& Transgender (LGBT) Community Center (the Center) and Asian Americans for Equality played a key role in NYC's success. These groups engaged community partners and policymakers. NYC Smoke-Free and the Center led walking tours of neighbourhoods with youth and politicians to raise awareness of the pervasiveness of tobacco marketing. The Center also coordinated meetings between youth and city council members, and incorporated its 'Flat Phil' campaigncreated by youth interns-into efforts to build policy support (see figure 1). ${ }^{21}$ Members from all three groups attended Community Board meetings across the city's boroughs to raise awareness of the problems and proposed policy solutions.

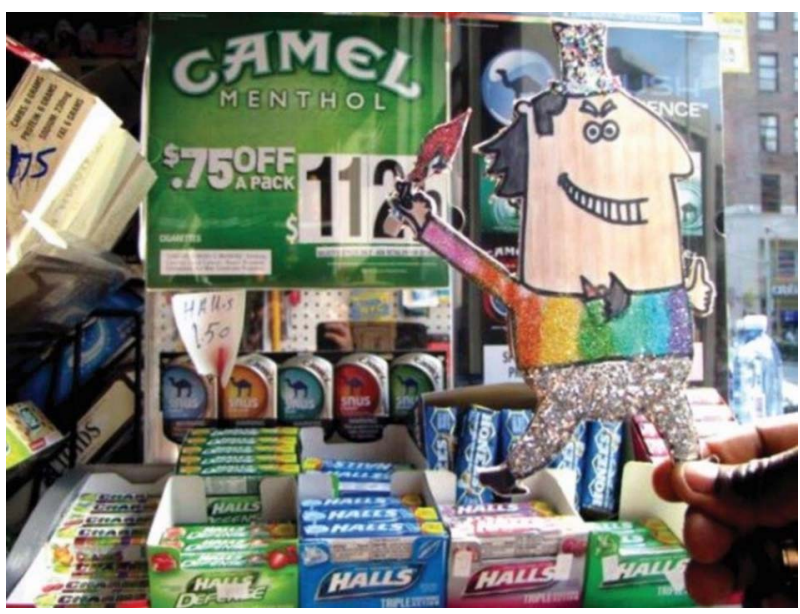

Figure 1 Flat Phil raising awareness of tobacco discounting in New York City.

\section{Being prepared to fight, and preparing retailers for policy change}

Partners stood united at the public hearing on the policies, telling stories of tobacco's impact on youth and adults, and citing evidence of the problem and of the policies' effectiveness. Representatives of NYC Smoke-Free and youth from the Center, along with a tobacco retailer, other citizens, research scientists, and the commissioners of Health and Finance testified at the hearing in support of the policies. The scientific evidence, policy expertise and compelling personal stories offered by the laws' supporters countered opposition from advocates for smokers' rights, retailer associations and the tobacco industry. ${ }^{22}$ In October 2013, the New York City Council voted on STE and Tobacco 21, passing both with large majorities. In November, the mayor signed the policies into law.

The city and its partners would face opposition from the industry and retailer associations again in a different forum. Soon after the policies passed, these groups filed a lawsuit claiming that the price-discounting component of STE violated the First Amendment, and was pre-empted by state and federal law. The city had anticipated this challenge and ultimately prevailed, when in June 2014, STE was upheld by a US District Court Judge. By August 2014, both policies were fully implemented. $^{23} 24$

The lawsuit only challenged the discount ban. As a result, even as the lawsuit was underway, the three city agencies began to roll out a robust communication strategy to educate retailers on how to comply with the new laws. Consumer Affairs invited every licenced tobacco retailer in the city to nine public information sessions and sent mass mailings to all retailers enclosing two signs required by the law (see figure 2). The Department of Health \& Mental Hygiene also made several fact sheets describing the new laws available on its website in five languages. ${ }^{16}$ The lawsuit concluded in time to incorporate the discount ban into the retailer information sessions.

\section{LESSONS LEARNT}

Since the passage of these laws in NYC, well over 100 jurisdictions in the USA, including the state of Hawaii, passed Tobacco 21 laws. $^{25}$ State legislators in a number of states, including California, Oregon, New York and New Jersey, have proposed state-level laws. Additionally, Chicago recently introduced Tobacco 21 legislation and a law, similar to STE, banning 


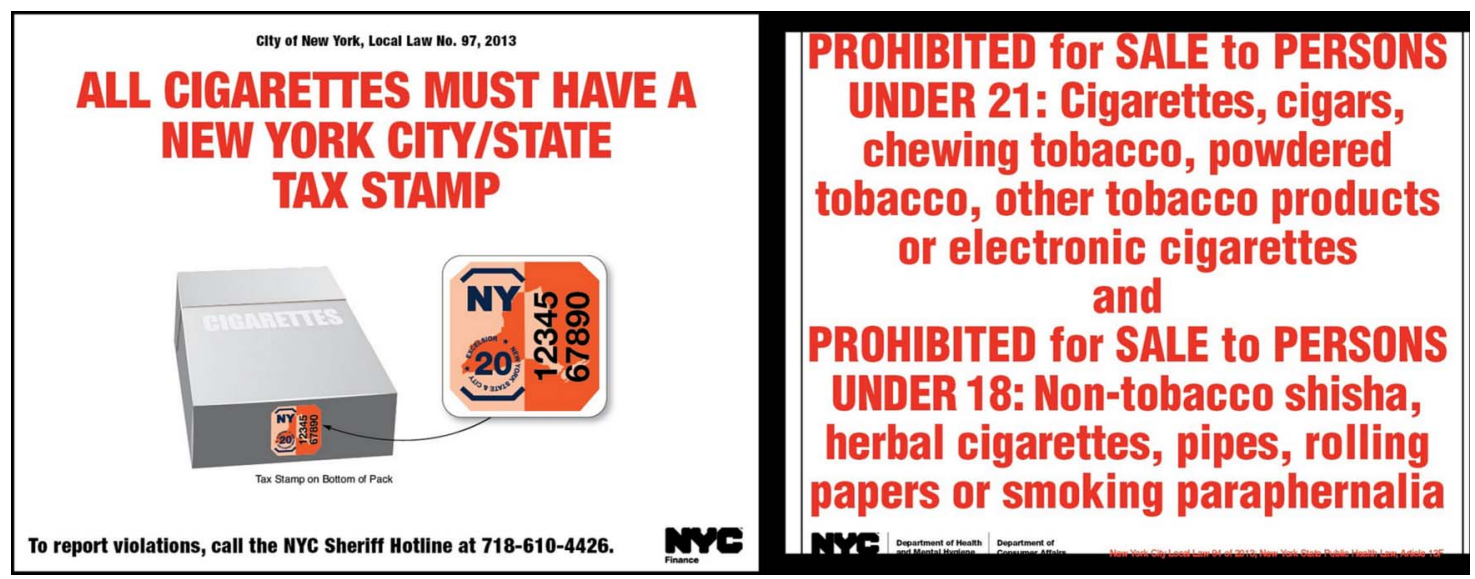

Figure 2 Signs for Sensible Tobacco Enforcement and Tobacco 21.

discounts on tobacco products and setting minimum prices for tobacco products. There are several lessons that municipalities that are considering similar policy work can learn from the NYC experience.

\section{Directly engage policymakers with their constituents}

For elected officials and even appointed neighbourhood representatives, constituent voices-especially those from youthproved important. "Politicians were way more interested in hearing from them [youth] than they ever were from me," said Erin McCarron, Smoke-Free Project Coordinator at the LGBT Community Center who accompanied youth advocates to meetings with city council members (McCarron, 2014). After learning about the extent of tobacco's impacts on their community, members from Asian Americans for Equality worked with NYC Smoke-Free in all five boroughs to organise small groups (2-5 people) to attend meetings of the city's 59 Community Boards where they spoke about the proposed policies to neighbours and neighbourhood leaders. NYC stakeholders relied heavily on bringing citizens together with their respective political representatives to demonstrate public support for the specific policies and tobacco control in general.

\section{Engage supportive retailers early on and maintain relationships}

Through its proxies, like convenience store associations, the tobacco industry promotes the argument that retailers will not support new tobacco control policies. ${ }^{26}$ However, not all store owners subscribe to tobacco industry orthodoxy. Most of them comply with age restrictions for tobacco sales, and many of them even support tobacco control, especially as it applies to youth, even if it may be against their economic interests. The challenge is engaging them and finding out which ones are willing to voice support for tobacco control and other public health issues. Heading the coalition of partners, NYC Smoke-Free engaged with business associations on the ground. Its representatives met with business improvement district organisations all over the city and were successful in establishing partnerships. Consumer Affairs and the Department of Health \& Mental Hygiene also engage with retailers through education sessions, mailings and online resources.

\section{Assess existing policies, incorporate existing efforts}

NYC already had some of the country's highest excise taxes and most comprehensive smoke-free air laws, and a host of other tobacco control laws. To design laws that complement or strengthen existing policies, staff from NYC agencies carefully evaluated existing policies and new opportunities. Just as the policies were built upon existing ones, efforts to educate and raise awareness about STE and Tobacco 21 were incorporated into ongoing youth programmes and other activities of NYC Smoke-Free, the Center and other partners. In addition, early in the process of passing laws like these, NYC developed a plan to evaluate their effectiveness, which included gathering baseline data before the laws passed and developing a plan to assess their effectiveness after they go into effect. The evaluation will assess trends in initiation and smoking over time among young adults and adolescents and compare this information with other age groups and regions to determine trends and effectiveness. These data are useful for building credibility with local lawmakers for future efforts and also help the tobacco control community in other jurisdictions.

\section{CONCLUSION}

NYC's visibility as a leader in tobacco control amplifies the impact of STE and Tobacco 21. Jurisdictions around the country, and even internationally, have been quick to follow with similar proposals. Combining an effective minimum price law, packaging requirements, and a ban on discounts is expected to increase prices and decreased access to tobacco. Coupling this suite of policies with Tobacco 21 further combats youth initiation and will help to reduce the heavy burden of tobacco use on the city. The policies owe their success to productive interagency cooperation and coordination, and city-wide partnerships with diverse stakeholders who create and maintain bridges between citizens and policymakers.

\section{What this paper adds}

- This paper provides an example of the successful passage of two tobacco control policies in a large US city.

- This paper highlights the important components of policy success - strong partnerships, substantial local data, and support from the public and elected officials - so that other communities might learn from and replicate these efforts.

Acknowledgements This paper contains some material that was originally published in a June 2015 report available here: http://publichealthlawcenter.org/ sites/default/files/resources/ASPiRE_2015_NYC_CaseStudy.pdf 
Contributors All authors have contributed towards the development, writing and review of this manuscript, comply with the Principles of the Ethical Practice of Public Health and do not have any conflicts of interest to report.

Funding Funding for this study was provided by grant number U01 CA154281 from the National Cancer Institute's State and Community Tobacco Control Initiative. The funders had no involvement in the study design, collection, analysis, writing or interpretation.

Competing interests None declared.

Ethics approval Institutional Review Board of the Washington University in St. Louis.

Provenance and peer review Not commissioned; internally peer reviewed.

Open Access This is an Open Access article distributed in accordance with the Creative Commons Attribution Non Commercial (CC BY-NC 4.0) license, which permits others to distribute, remix, adapt, build upon this work non-commercially, and license their derivative works on different terms, provided the original work is properly cited and the use is non-commercial. See: http://creativecommons.org/ licenses/by-nc/4.0/

\section{REFERENCES}

1 U.S. Department of Health and Human Services. Preventing tobacco use among youth and young adults : a report of the Surgeon General. Atlanta, GA: U.S. Dept. of Health and Human Services, Public Health Service, Centers for Disease Control and Prevention, National Center for Chronic Disease Prevention and Health Promotion, 2012:xiv, 899 p.

2 Center for Public Health Systems Science. Reducing Cheap Tobacco \& Youth Access. St. Louis, MO: Center for Public Health Systems Science at the Brown School at Washington University, the National Cancer Institute, and State and Community Tobacco Control Research, 2015. https://cphss.wustl.edu/Products/ ProductsDocuments/ASPiRE_2015_NYC_CaseStudy.pdf (accessed 24 May 2016).

3 DiFranza JR, Coleman M. Sources of tobacco for youths in communities with strong enforcement of youth access laws. Tob Control 2001;10:323-8.

4 Hammond D. Smoking behaviour among young adults: beyond youth prevention. Tob Control 2005;14:181-5.

5 Stienberg MB, Delnevo CD. Increasing the "Smoking Age": the right thing to do. Ann Intern Med 2013;159:558-9.

6 U.S. Surgeon General, National Center for Chronic Disease Prevention and Health Promotion Office on Smoking and Health. Preventing tobacco use among youth and young adults. We can make the next generation tobacco-free : a report of the Surgeon General. Atlanta, GA. and Washington, D.C: U.S. Dept. of Health and Human Services, Public Health Service, Centers for Disease Control and Prevention, National Center for Chronic Disease Prevention and Health Promotion, 2012.

7 Steinberg MB, Delnevo CD. Increasing the "smoking age": the right thing to do. Ann Intern Med 2013;159:558-9.

8 Campaign for Tobacco Free Kids. Increasing the Minimum Legal Sale Age for Tobacco Products to 21. Secondary Increasing the Minimum Legal Sale Age for Tobacco Products to 21 2014. http://www.tobaccofreekids.org/research/factsheets/ pdf/0376.pdf

9 Institute of Medicine of the National Academies. Committee on the Public Health Implications of Raising the Minimum Age for Purchasing Tobacco Products. Public Health Implications of Raising the Minimum Age of Legal Access to Tobacco Products, 2015. http://www.nationalacademies.org/hmd/ /media/Files/Report\%
20Files/2015/TobaccoMinAge/tobacco_minimum_age_report_brief.pdf (accessed 24 May 2016).

10 Center for Public Health Systems Science. Point-of-Sale Report to the Nation: the Tobacco Retail and Policy Landscape. St. Louis, MO: Center for Public Health Systems Science at the Brown School at Washington University, the National Cancer Institute, and State and Community Tobacco Control Research, 2014.

11 Reitzel LR, Cromley EK, Li Y, et al. The effect of tobacco outlet density and proximity on smoking cessation. Am J Public Health 2011;101:315-20.

12 Watkins KL, Regan SD, Nguyen N, et al. Advancing cessation research by integrating EMA and geospatial methodologies: associations between tobacco retail outlets and real-time smoking urges during a quit attempt. Nicotine Tob Res 2014;16(Suppl 2):S93-101.

13 White VM, White MM, Freeman K, et al. Cigarette promotional offers: who takes advantage? Am J Prev Med 2006;30:225-31.

14 Feighery EC, Ribisl KM, Schleicher NC, et al. How do minimum cigarette price laws affect cigarette prices at the retail level? Tob Control 2005; 14:80-5.

15 McLaughlin I, Pearson A, Laird-Metke E, et al. Reducing tobacco use and access through strengthened minimum price laws. Am J Public Health 2014; 104:1844-50.

16 Schroth K. Interview, bureau of chronic disease prevention and tobacco control. New York City Department of Health and Mental Hygiene, 2014.

17 Change Lab Solutions. Limiting "teen-friendly" cigars: what communities can do. Secondary Limiting "teen-friendly" cigars: what communities can do 2012. http:// changelabsolutions.org/sites/default/files/documents/Limiting_Teen-Friendly_Cigars_ FINAL_20120119.pdf

18 Boston M. A Regulation Limiting Tobacco and Nicotine Access by Youth ("Youth Access Regulation"). Secondary A Regulation Limiting Tobacco and Nicotine Access by Youth ("Youth Access Regulation"), 2011. http://www.bphc.org/ boardofhealth/regulations/Documents/Tobacco_Control_Youth_Access_ Regulation.pdf

19 Grimshaw V. Interview, bureau of chronic disease prevention and tobacco control. New York City Department of Health and Mental Hygiene, 2014.

20 New York City Department of Health and Mental Hygiene and Department of Consumer Affairs. New Law Prohibiting Sale of Cigarettes, Tobacco Products and Electronic Cigarettes to People Under Age 21 in New York City. http://www.nyc.gov/ html/doh/downloads/pdf/smoke/tobacco-21-faq.pdf (accessed 16 Jan 2015).

21 NYC Smoke Free. Flat Phil. Secondary Flat Phil 2015. http://nycsmokefree.org/ flatphil

22 New York City Council Committee on Health. Hearing on Intros. 1020, 1021, and 250A, May 2, 2013. Secondary Hearing on Intros. 1020, 1021, and 250A, May 2, 2013 2013. http://council.nyc.gov/html/home/home.shtml

23 Tobacco companies challenge NYC coupon ban. AP Online. Press Association, Inc 2014. from: https://www.highbeam.com/doc/1A1-1497f39c14e149499b7decef67d 69f35.html (accessed 24 May 2016).

24 Counter Tobacco. New York City Point-of-Sale Legislation. Secondary New York City Point-of-Sale Legislation, 2013. http://countertobacco.org/new-york-city-point-salelegislation

25 Lagreid P. Suffolk County, NY Raises Tobacco Purchase Age to 21 (Update). Secondary Suffolk County, NY Raises Tobacco Purchase Age to 21 (Update) 2014. http://halfwheel.com/suffolk-county-n-y-raises-tobacco-purchase-age-21/ 51561

26 Glantz SA, Smith LR. The effect of ordinances requiring smoke-free restaurants and bars on revenues: a follow-up. Am J Public Health 1997;87:1687-93. 